Buletin Ilmiah Math. Stat. dan Terapannya (Bimaster)

Volume 08, No. 3 (2019), hal 505 - 514.

\title{
ANALISIS KUALITAS PELAYANAN PUSKESMAS DENGAN METODE SERVQUAL DAN TRIZ (Studi Kasus: Puskesmas Parit Haji Husin II Kec. Pontianak Tenggara)
}

\author{
Syafitri Wulandari, Evy Sulistianingsih, Nurfitri Imro'ah
}

\begin{abstract}
INTISARI
Metode Service quality (Servqual) merupakan metode yang digunakan untuk mengukur kualitas layanan yang didasarkan atas lima dimensi. Lima dimensi Servqual yaitu tangiable, reliability, responsiveness, assurance, dan emphaty dan terdiri dari dua puluh variabel pertanyaan. Metode Servqual diukur dari penilaian antara persepsi dengan harapan yang diinginkan mengetahui informasi tentang kualitas pelayanan. Teoriya Resheniya Izobretatelskikh Zadatch (TRIZ) merupakan metode pemecahan masalah terstruktur yang menunjukkan bagaimana cara memecahkan hambatan yang muncul. Tujuan penelitian ini menganalisis kualitas pelayanan Puskesmas Parit Haji Husin II dengan menggunakan metode Servqual, serta mengusulkan dan memberikan solusi perbaikan peningkatan kualitas pelayanan Puskesmas Parit Haji Husin II dengan Metode TRIZ. Berdasarkan hasil penelitian dengan metode Servqual terdapat enam variabel kualitas pelayanan yang belum memuaskan harapan pasien. Enam variabel tersebut yaitu perhatian terhadap keluhan pasien, kebersihan, kerapian dan kenyamanan ruangan, tindakan cepat pada saat pasien membutuhkan medis, prosedur pelayanan tidak berbelit-belit, dan pelayanan penerimaan cepat dan tepat. Solusi perbaikan dengan metode TRIZ yang dapat digunakan adalah principle persiapan, dan principle transformasi.
\end{abstract}

Kata Kunci : Servqual, TRIZ, inventive principle.

\section{PENDAHULUAN}

Kepuasan pasien adalah suatu tingkat perasaan pasien yang timbul sebagai akibat dari kinerja pelayanan kesehatan yang diperolehnya setelah pasien membandingkannya dengan apa yang diharapkannya [1]. Kepuasan pasien dapat dilihat dari bagaimana kualitas pelayanan yang diberikan Puskesmas dalam memenuhi kebutuhan pasien. Kualitas tingkat pelayanan terhadap kepuasan pasien merupakan proses yang komplit, sehingga akan sehingga pada akhirnya akan menyangkut manajemen Puskesmas secara keseluruhan. Metode pengukuran kualitas yang sering digunakan adalah metode Service Perfomance (SERVPERF), metode Importance Perfomance Analysis (IPA), metode Service Quality (SERVQUAL). Proses desain kualitas dapat menggunakan metode Quality Fuction Deployment (QFD) dan Kano. Metode usulan perbaikan dapat menggunakan metode Teoriya Resheniya Izobretatelskikh Zadatch (TRIZ).

Metode yang digunakan pada penelitian ini adalah metode Servqual dan TRIZ. Metode Servqual memiliki beberapa kelebihan diantaranya telah diakui sebagai standar dalam kualitas layanan, dan memiliki prosedur analisis standar yang sehingga memudahkan dalam interpretasi hasil [2]. Kelebihan metode TRIZ adalah kemampuannya mengorganisir dan menstrukturkan tahapan-tahapan dalam inovasi sehingga meminimalisir waktu dan biaya [3]. Metode Servqual diukur dari penilaian antara persepsi pasien dengan harapan yang diinginkan pasien agar pihak Puskesmas mengetahui informasi tentang kualitas pelayanan. TRIZ adalah metodologi sistematis berbasis pengetahuan manusia dari pemecahan masalah inventif [4]. IPA merupakan alat bantu yang digunakan untuk membandingkan sejauh mana antara kinerja yang dirasakan dibanding dengan tingkat kepuasan yang diinginkan. 
Adapun tujuan yang dicapai dari penelitian ini adalah

1. Menganalisis kualitas pelayanan Puskesmas Parit Haji Husin II dengan menggunakan metode Servqual

2. Mengusulkan dan memberikan solusi perbaikan peningkatan kualitas pelayanan Puskesmas Parit Haji Husin II dengan Metode TRIZ.

Batasan masalah dalam penelitian ini yaitu objek penelitian adalah kualitas pelayanan Puskesmas Parit Haji Husin II. Responden dalam penelitian ini adalah pasien yang berkunjung ke Puskesmas Parit Haji Husin II pada bulan Juli 2018. Kualitas pelayanan Puskesmas diukur dengan menggunakan metode Servqual, dan usulan perbaikan berdasarkan metode TRIZ.

Metode yang digunakan dalam pengumpulan data yaitu menggunakan data primer yang diperoleh dengan cara menyebarkan kuesioner secara langsung kepada pasien Puskemas Parit Haji Husin II. Tahapan di mulai dengan menentukan jumlah sampel kemudian menyusun kuesioner. Setelah penyusunan kuesioner maka kuesioner awal disebarkan kepada pasien Puskesmas Parit Haji Husin II. Selanjurnya menentukan sampel dan penyebaran kuesioner akhir. Perhitungan Servqual dan usulan perbaikan dengan metode TRIZ.

\section{DIMENSI MUTU PELAYANAN KESEHATAN}

Ada lima dimensi utama dalam kualitas pelayanan. Kelima dimensi utama kualitas layanan tersebut adalah [2]:

1. Tangiable (Bukti Langsung). Dimensi ini berkaitan dengan fasilitas fisik peralatan, penampilan personal dan alat-alat.

2. Reability (Keandalan). Dimensi ini berkaitan dengan kemampuan untuk memberikan pelayanan yang dijanjikan kepada konsumen dengan segera, akurat dan memuaskan.

3. Responsiveness (Daya Tanggap). Dimensi ini berkaitan dengan rasa tanggung jawab dari pemberi jasa untuk membantu konsumen dan memberikan pelayanan yang tanggap.

4. Assurance (Jaminan). Dimensi ini berkaitan dengan pengetahuan, kesopanan dan kemampuan personil untuk menimbulkan rasa percaya, aman dan yakin kepada konsumen.

5. Emphaty (Empati). Dimensi ini meliputi kemudahan dalam melakukan hubungan komunikasi yang baik, perhatian pribadi dan memahami keinginan konsumen.

\section{PENENTUAN SAMPEL}

Sampel adalah sebagian anggota populasi yang dapat mewakili populasi itu sendiri. Penelitian ini sampel yang akan diambil menggunakan rumus Linear Time Function (LTF), yaitu penentuan jumlah sampel yang didasarkan estimasi kendala waktu. Perhitungan jumlah sampel menggunakan metode LTF ditunjukkan sebagai berikut [5]:

$$
n=\frac{T-t_{0}}{t_{1}}
$$

Keterangan:

$T$ = waktu yang tersedia untuk penelitian

$t_{0}=$ waktu pengambilan sampel penelitian

$t_{1}=$ waktu yang dibutuhkan responden untuk mengisi kuesioner

\section{KUESIONER}

Kuesioner adalah satu set pertanyaan yang tersusun secara sistematis dan standar sehingga pertanyaan yang sama dapat diajukan kepada respoden. Jenis pertanyaan kuesioner dapat dibedakan menjadi pertanyaan terbuka dan tertutup. Pertanyaan terbuka memungkinkan responden memberikan jawaban yang dikehendaki dengan kata-kata yang dipilihnya sendiri. Pertanyaan tertutup membatasi jawaban responden dengan keharusan memilih diantara jawaban-jawaban yang yang sudah tercantum [6]. 


\section{SKALA PENGUKURAN}

Skala pengukuran adalah kesepakatan yang digunakan sebagai acuan atau tolak ukur untuk menentukan panjang pendeknya interval yang ada pada alat ukur sehingga alat ukur tersebut bila digunakan dalam pengukuran akan menghasilkan data. Skala likert digunakan untuk mengukur sikap pendapat persepsi seseorang tentang gejala atau masalah yang ada dimasyarakat atau yang dialaminya [7].

\section{METODE SERVICE QUALITY (SERVQUAL)}

Metode Servqual dapat digunakan untuk menganalisis kebutuhan konsumen sehingga perusahaan dapat melakukan perbaikan-perbaikan terhadap kualitas jasa yang diberikan sehingga diharapkan konsumen merasa puas dengan pelayanan yang diberikan. Metode servqual secara garis besar terbagi menjadi dua bagian harapan dan persepsi.

Langkah pertama perhitungan Servqual adalah dengan menghitung rata-rata skor dari tiap variabel harapan dan persepsi sebagai berikut [2].

$$
\begin{gathered}
\bar{E}_{j}=\frac{\sum_{i=1}^{n} E_{i j}}{n} \\
\bar{P}_{j}=\frac{\sum_{i=1}^{n} P_{i j}}{n}
\end{gathered}
$$

dimana $\bar{E}_{j}$ merupakan rata-rata sampel harapan, $E_{i j}$ adalah jumlahan nilai harapan. $\bar{P}_{j}$ merupakan ratarata sampel persepsi, $P_{i j}$ adalah jumlahan nilai persepsi, dan $n$ merupakan jumlah responden.

Nilai Servqual diperoleh dari hasil pengurangan nilai rata-rata persepsi dengan nilai rata-rata harapan. Perhitungan nilai Servqual dapat dilihat sebagai berikut [2]:

$$
S S_{j}=\bar{P}_{j}-\bar{E}_{j}
$$

\section{METODE IMPORTANCE PERFOMANCE ANALYSIS (IPA)}

IPA merupakan metode pengukuran kualitas pelayanan untuk mengetahui hubungan antara kinerja konsumen dengan prioritas peningkatan kualitas [2]. Tingkat kesesuaian merupakan hasil perbandingan antara skor kinerja dengan kepentingan, sehingga tingkat kesesuaian inilah yang akan menentukan skala prioritas yang akan dipakai dalam penanganan.

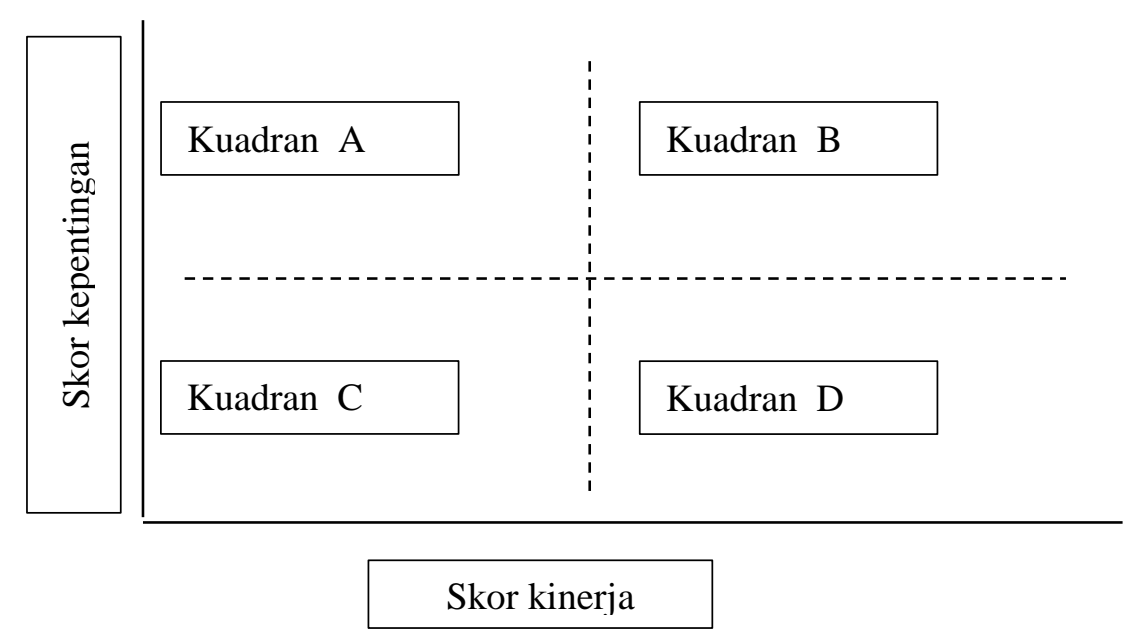

Gambar 1 Kuadran IPA 
Interpretasi untuk diagram kuadran IPA adalah kuadran A yaitu atribut yang terletak pada posisi ini dianggap sebagai faktor yang kepentingan nya tinggi tetapi kinerja yang dilakukan rendah atau belum memuaskan bagi responden. Atribut yang terletak pada kuadran A merupakan prioritas yang harus ditingkatkan. Kuadran B yaitu atribut yang terletak pada posisi ini dianggap penting dan diharapkan sebagai faktor penunjang bagi kepuasan konsumen. Kuadran B responden mengharapkan agar pihak manajemen atau penyedia jasa mempunyai kewajiban untuk memastikan bahwa kinerja yang dihasilkan dapat mempertahankan prestasi yang telah dicapai. Kuadran $\mathrm{C}$ yaitu atribut yang terletak pada posisi ini kurang dianggap penting tetapi tingkat kepuasan konsumen cukup baik namun konsumen mengabaikan atribut yang terletak pada posisi ini sehingga pihak manajemen tidak perlu memprioritaskan tetapi pihak penyedia jasa boleh melakukan perbaikan atau peningkatan kerja. Kuadran D yaitu atribut yang terletak pada posisi ini dianggap kurang penting tetapi tingkat kepuasan dari konsumen sangat memuaskan atau bisa di bilang kinerja dari pegawai yang berlebihan.

\section{METODE TEORIYA RESHENIYA IZOBRETATELSKIKH ZADATCH (TRIZ)}

TRIZ merupakan singkatan dalam bahasa Rusia yaitu Teoriya Resheniya Izobretatelskikh Zadatch. Ditemukan oleh Genrich Saulovich Atshuller dari Uni Soviet, Jika diterjemahkan dalam bahasa Inggris menjadi Theory of Inventive Problem Solving. TRIZ adalah metodologi sistematis berbasis pengetahuan manusia dari pemecahan masalah inventif [4]. Kemudian metode TRIZ juga dapat menghasilkan inovasi-inovasi dan menciptakan solusi dari suatu masalah. Tahapan dalam metode TRIZ ada empat yaitu solusi awal perbaikan, pemodelan masalah dan analisis kontradiksi, eliminasi kontradiksi berdasarkan TRIZ inventive principles, dan solusi perbaikan dengan menggunakan metode TRIZ. Penjelasan tahapan metode TRIZ dapat dilihat sebagai berikut [4]:

1. Solusi awal perbaikan. Tujuan dari tahap ini adalah untuk mengidentifikasi dan mengumpulkan masalah dalam operasi jasa/pelayanan, kemudian melakukan analisis untuk menangkap informasi atas masalah.

2. Pemodelan masalah dan analisis kontradiksi. Pemodelan masalah dalam TRIZ menggunakan teknik formulasi masalah. Solusi yang didapat diterjemahkan dalam parameter teknik 39 TRIZ yang dikembangkan oleh Altshuller. Parameter teknik dibagi menjadi dua, yaitu improving feature dan worsening feature. Improving feature adalah hal yang ingin dicapai untuk perbaikan kualitas. Worsening feature adalah hal yang menjadi efek samping dari improving feature.

3. Eliminasi kontradiksi berdasarkan TRIZ inventive principle. TRIZ menyediakan 40 inventive principles, dan contradiction matrix Athsuller. Inventive principles dianggap sebagai teknik yang paling dapat diakses dan berguna. Aplikasi membuktikan bahwa teknik ini tidak hanya efektif untuk mengeliminasi kontradiksi pada masalah teknik tetapi juga efektif untuk masalah non teknik.

4. Solusi perbaikan dengan menggunakan metode TRIZ. Setelah mengeliminasi kontradiksi, sekelompok solusi harus dibentuk. Tujuan utama evaluasi ini adalah untuk mengidentifikasi ide terbaik berdasarkan kondisi ideal. Teknik untuk mengevaluasi solusi disebut ideal final result (IFR).

\section{STUDI KASUS}

Penelitian ini, mengolah data primer yang diperoleh dengan cara menyebarkan kuesioner secara langsung kepada responden. Kuesioner penelitian menggunakan skala likert. Pada penelitian ini, jumlah kuisioner yang disebar sebanyak 50 eksemplar. Kuesioner yang kembali juga sebanyak 50 eksemplar 
Kuesioner yang kembali juga sebanyak 50 eksemplar. Penelitian dilakukan di Puskesmas Parit Haji Husin II Kec. Pontianak Tenggara pada bulan Juli 2018. Penyebaran kuesioner dilakukan selama 8 hari kerja mulai dari tanggal 23 Juli 2018 sampai dengan 31 Juli 2018. Identifikasi pertanyaan dilakukan untuk mendapatkan pertanyaan mengenai kualitas pelayanan Puskesmas.

\section{PERHITUNGAN SERVQUAL}

Nilai Servqual diperoleh dari hasil pengurangan nilai rata-rata persepsi dengan nilai rata-rata harapan. Hasil selengkapnya dapat dilihat pada Tabel 1 berikut:

Tabel 1 Perhitungan Nilai Servqual

\begin{tabular}{|c|c|}
\hline Kriteria Layanan & Nilai Servqual \\
\hline 1. Jadwal pemeriksaan yang tepat waktu & $-0,14$ \\
\hline 2. Pelayanan loket cepat dan tepat & 0,14 \\
\hline 3. Pelayanan penerimaan cepat dan tepat & $-0,02$ \\
\hline $\begin{array}{l}\text { 4. Prosedur pelayanan tanpa memandang status } \\
\text { sosial }\end{array}$ & 0,38 \\
\hline 5. Kemampuan dokter dan perawat cepat tanggap & 0,1 \\
\hline $\begin{array}{l}\text { 6. Petugas memberikan informasi yang jelas dan } \\
\text { mudah dimengerti pasien }\end{array}$ & 0,38 \\
\hline $\begin{array}{l}\text { 7. Dokter didampingi perawat dalam memeriksa } \\
\text { pasien }\end{array}$ & 0,36 \\
\hline $\begin{array}{l}\text { 8. Tindakan cepat pada saat pasien membutuhkan } \\
\text { pelayanan medis }\end{array}$ & $-0,12$ \\
\hline $\begin{array}{l}\text { 9. Petugas mampu menjaga kerahasiaan diagnosa } \\
\text { penyakit }\end{array}$ & 0,18 \\
\hline $\begin{array}{l}\text { 10. Pengetahuan dan kemampuan dokter, perawat, } \\
\text { dan petugas lainnya dalam bertugas }\end{array}$ & 0,44 \\
\hline $\begin{array}{l}\text { 11. Berupa jaminan kesembuhan terhadap } \\
\text { pelayanan }\end{array}$ & 0,4 \\
\hline $\begin{array}{l}\text { 12. Keterampilan dokter, perawat, dan petugas } \\
\text { lainnya baik }\end{array}$ & 0,26 \\
\hline $\begin{array}{l}\text { 13. Memberikan perhatian secara khusus pada } \\
\text { setiap pasien }\end{array}$ & 0,2 \\
\hline $\begin{array}{l}\text { 14. Perhatian terhadap keluhan pasien dan } \\
\text { keluarganya }\end{array}$ & $-0,56$ \\
\hline 15. Prosedur pelayanan tidak berbelit-belit & $-0,1$ \\
\hline $\begin{array}{l}\text { 16. Antara petugas dan pasien terjalin komunikasi } \\
\text { yang baik }\end{array}$ & 0,32 \\
\hline 17. Pelayanan oleh petugas ramah dan sopan & 0,52 \\
\hline 18. Kebersihan, kerapian dan kenyamanan ruangan & $-0,54$ \\
\hline 19. Penataan ruangan tertata baik & 0,5 \\
\hline $\begin{array}{l}\text { 20. Pelengkapan, kesiapan dan kebersihan alat-alat } \\
\text { pemeriksaan yang terjamin }\end{array}$ & 0,5 \\
\hline
\end{tabular}


Berdasarkan hasil pengolahan data sebanyak 20 variabel, 14 variabel bernilai positif dan 6 variabel bernilai negatif. Variabel yang bernilai positif menunjukkan bahwa variabel tersebut sudah memuaskan harapan pasien, sedangkan variabel yang bernilai negatif menunjukkan bahwa variabel tersebut menjadi masalah dalam pelayanan karena dianggap belum mampu memenuhi harapan pasien Puskesmas Parit Haji Husin II. Nilai Servqual terbesar terdapat pada variabel $X_{17}$ yaitu pelayanan oleh petugas ramah dan sopan sebesar 0,52. Responden menganggap bahwa petugas yang ada di Puskesmas Parit Haji Husin II telah memaksimalkan pelayanan yang telah diterapkan oleh Puskesmas yaitu dengan memberikan senyum, salam, sapa, sopan dan santun (5S) kepada setiap pasien yang datang ke Puskesmas.

\section{PERHITUNGAN IPA}

IPA mengkombinasikan pengukuran pada dimensi ekspektasi dan kepentingan. Dimensi tersebut di plotkan ke dalam nilai kepentingan sebagai sumbu vertikal sedangkan nilai ekpektasi sebagai sumbu diagonal. Selanjutnya menggunakan nilai rata-rata yang terdapat pada dimensi kepentingan dan ekspektasi sebagai pusat pemotongan garis.

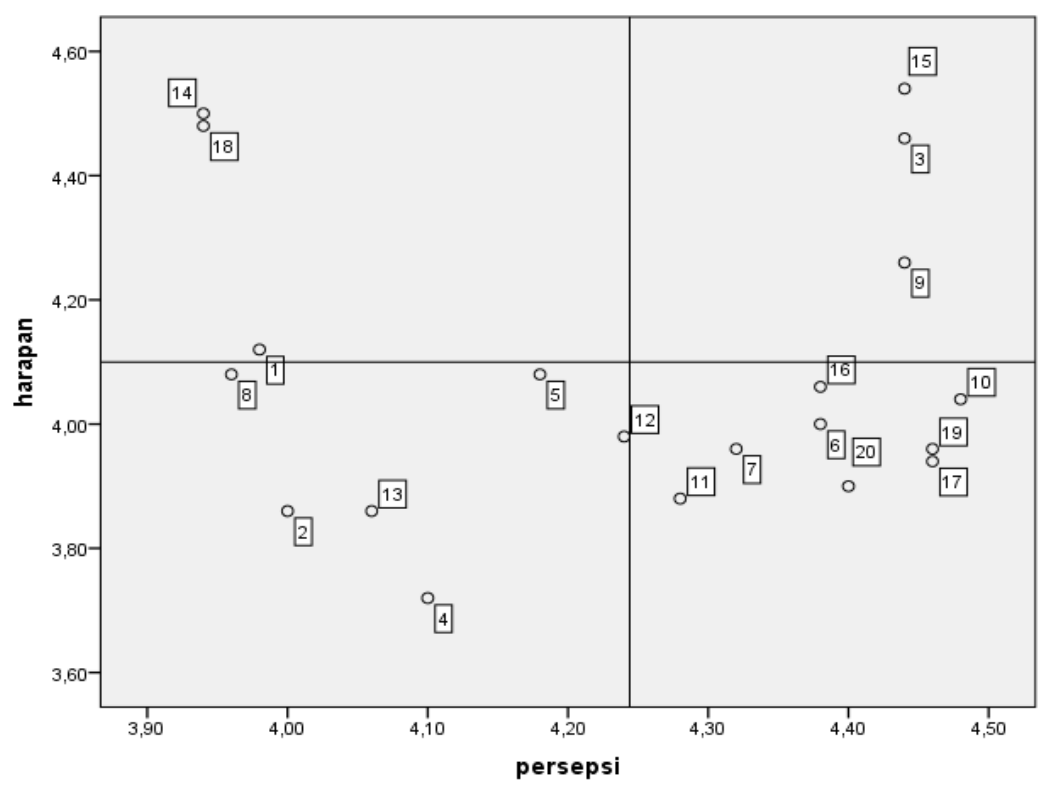

Gambar 2 Kuadran IPA

a. Kuadran A (Prioritas Utama)

Variabel yang berada didalam kuadran A menunjukkan variabel kualitas jasa yang memiliki tingkat kepuasan tinggi atau di atas nilai rataan, tetapi memiliki tingkat keadaan dinilai rendah. Variabel di kuadran A perlu mendapatkan perbaikan. Variabel yang masuk dalam kuadran A adalah variabel 14, 18, dan 1.

b. Kuadran B (Pertahankan)

Kuadran B menunjukkan variabel yang penanganannya perlu dipertahankan karena tingkat keadaan telah sesuai dengan harapan pasien. Variabel yang termasuk di kuadran B adalah 15, 3, dan 9.

c. Kuadran C (Perioritas Rendah)

Kuadran $\mathrm{C}$ menunjukkan variabel yang dianggap kurang penting oleh pelanggan dimana kinerjanya dianggap biasa. Variabel yang termasuk di kuadran $C$ adalah 8, 5, 13, 2 dan 4. 
d. Kuadran D (Berlebihan)

Variabel yang berada didalam kuadran D menunjukkan variabel yang dianggap berlebihan pelaksanaannya disebabkan karena pelanggan menganggap tidak terlalu penting. Variabel yang termasuk di kuadran D adalah 16, 10, 12, 6, 7, 20, 19, dan 17.

\section{PERANCANGAN USULAN MENGGUNAKAN TRIZ}

Langkah 1: Solusi Awal

Berdasarkan nilai Servqual yang diperoleh, ada enam kriteria layanan yang memiliki nilai Servqual lebih kecil. Hal ini berarti bahwa keenam kriteria layanan tersebut menjadi prioritas utama bagi pihak Puskesmas untuk memperbaiki kualitas layanannya. Kualitas perbaikan sesuai prioritas dapat dilihat pada Tabel 2 berikut.

Tabel 2 Kriteria Layanan

\begin{tabular}{lccl}
\hline Prioritas & $\begin{array}{c}\text { Nilai } \\
\text { Servqual }\end{array}$ & Variabel & \multicolumn{1}{c}{ Kriteria Layanan } \\
\hline 1 & $-0,56$ & $X_{14}$ & Perhatian terhadap keluhan pasien dan keluarganya \\
2 & $-0,54$ & $X_{18}$ & Kebersihan, kerapian dan kenyamanan ruangan \\
3 & $-0,14$ & $X_{1}$ & Jadwal pemeriksaan yang tepat waktu \\
4 & $-0,12$ & $X_{8}$ & Tindakan cepat pada saat pasien membutuhkan pelayanan \\
& & & medis \\
6 & $-0,1$ & $X_{15}$ & Prosedur pelayanan tidak berbelit-belit \\
6 & $-0,02$ & $X_{3}$ & Pelayanan penerimaan cepat dan tepat \\
\hline
\end{tabular}

Berdasarkan harapan pasien dari keenam kriteria tersebut disusun solusi awal untuk pemecahan masalahnya. Solusi awal berdasarkan masalah tersebut disusun dengan cara berdiskusi bersama Kepala Puskesmas Parit Haji Husin II. Solusi awal berdasarkan masalah dapat dilihat pada Tabel 3 berikut ini:

Tabel 3 Solusi Awal

\begin{tabular}{ccl}
\hline Prioritas & Variabel & \multicolumn{1}{c}{ Solusi Awal } \\
\hline 1 & $X_{14}$ & Penambahan kotak pengaduan di depan loket pendaftaran \\
2 & $X_{18}$ & Petugas harus lebih memperhatikan Kebersihan \\
3 & $X_{1}$ & Petugas Puskesmas datang tepat waktu sesuai jadwal layanan \\
4 & $X_{8}$ & Evaluasi petugas \\
5 & $X_{15}$ & Memasang $x$-banner alur pelayanan di samping pintu masuk \\
6 & $X_{3}$ & Pelatihan petugas \\
\hline
\end{tabular}

Langkah 2: Pemodelan Masalah dan Analisis Kontradiksi

a. Improving Feature

Tahap pertama penyelesaian masalah menggunakan metode TRIZ, yang dicari yaitu improving feature. Improving Feature adalah solusi awal untuk perbaikan kualitas pelayanan. Keenam solusi awal disesuaikan dengan tabel improving feature dari 39 parameter. Hasil selengkapnya dapat dilihat pada Tabel 4 berikut:

Tabel 4 Improving Feature

\begin{tabular}{lr}
\hline Keterangan & Parameter Teknik \\
\hline Penambahan kotak pengaduan di depan loket pendaftaran & Ease of repair (\#34) \\
Petugas harus lebih memperhatikan Kebersihan & Reliability (\#27) \\
Petugas Puskesmas datang tepat waktu sesuai jadwal & Speed (\#9) \\
layanan & \\
\hline
\end{tabular}


Tabel 4 Improving Feature (lanjutan)

\begin{tabular}{lr}
\hline Keterangan & Parameter Teknik \\
\hline Evaluasi petugas & Productivity (\#39) \\
Memasang $x$-banner alur pelayanan di samping pintu & Ease of manufacture (\#32) \\
masuk & Productivity (\#39) \\
Pelatihan petugas & Proditis \\
\hline
\end{tabular}

\section{b. Worsening Feature}

Tahap kedua adalah worsening feature. Worsening feature merupakan dampak dari solusi awal perbaikan ketika hal itu dilakukan. Setelah menentukan parameter teknik improving feature, kemudian dicari worsening feature dengan mempertimbangkan improving feature dari tiap variabel Servqual. Hasil selengkapnya dapat dilihat pada Tabel 5 berikut:

Tabel 5 Worsening Feature

\begin{tabular}{lr}
\hline Keterangan & Parameter Teknik \\
\hline Kecepatan feedback yang diperoleh pasien & Speed (\#9) \\
Memaksimalkan petugas kebersihan terhadap & Force (\#10) \\
kebersihan petugas & \\
Adaptasi petugas karena datang harus lebih awal & Adaptability (\#35) \\
sebelum memulai layanan & Duration of action by \\
Waktu yang digunakan petugas untuk dapat bekerja & a moving object (\#15) \\
sesuai dengan tanggung jawabnya & $\begin{array}{c}\text { Amount of substance (\#26) } \\
\text { Biaya yang dikeluarkan Puskesmas } \\
\text { Biaya yang dikeluarkan untuk pelatihan petugas }\end{array}$ \\
& Amount of substance (\#26)
\end{tabular}

Langkah 3: Eliminasi Kontradiksi Berdasarkan TRIZ Inventive Principle

Tahap berikutnya adalah mencari inventive principles berdasarkan hasil dari pertemuan improving feature dan worsening feature pada matriks kontradiksi. Pertemuan dari tiap elemen akan menghasilkan nomor-nomor inventive principles yang bertujuan untuk mencari dasar dari usulan untuk solusi peningkatan kualitas pelayanan. Hasil selengkapnya dapat dilihat pada Tabel 6 berikut:

Tabel 6 Inventive Principles

\begin{tabular}{lr}
\hline Improving Feature vs Worsening Feature & Inventive Principles \\
\hline Ease of repair vs speed & 34,9 \\
Reliability vs force & $8,28,10,3$ \\
Speed vs adaptability & $15,10,26$ \\
Productivity vs duration of action by a moving object & $35,10,2,18$ \\
Shape vs amount of substance & 36,22 \\
productivity vs Loss of time & 35,38
\end{tabular}

Langkah 4: Usulan Perbaikan TRIZ Berdasarkan Hasil Inventive Principles

Tahap ini adalah tahap terakhir untuk mencari pertimbangan dari solusi awal yang digunakan untuk meningkatkan kualitas dari enam variabel prioritas. Pertimbangan solusi dari satu variabel dapat dicari dengan menggunakan berderet principles yang dipakai. Principles yang dapat dipakai adalah principle 10 (principles persiapan), principle 35 (principles transformasi). 
Solusi awal dari pihak manajemen Puskesmas Parit Haji Husin II dipadukan dengan solusi dari inventive principles.

Usulan solusi perbaikan berdasarkan principles 35 (principles transformasi) sub prinsip A yaitu "mengubah parameter sebuah objek atau sistem".

1. Sebaiknya Puskesmas Parit Haji Husin II mengubah posisi atau letak kotak pengaduan pelayanan didepan loket pendaftaran. Kotak pengaduan yang disimpan didepan loket pendaftaran diharapkan dapat mengoptimalkan keluhan pasien karena tempat kotak pengaduan yang mudah dijangkau dan dapat dipantau oleh petugas loket.

2. Sebaiknya Kepala Puskesmas mewajibkan apel pagi kepada seluruh petugas Puskesmas, jika melanggar ada sangsi berupa teguran yang diberikan pada saat petugas yang melanggar mengikuti apel pagi selanjutnya.

Usulan solusi perbaikan berdasarkan principles persiapan sub prinsip A yaitu "Melakukan tindakan persiapan untuk sebuah objek atau sistem baik lengkap maupun sebagian dari sistem atau objek tersebut".

1. Sebaiknya petugas kebersihan mengatur waktu pembersihan sebelum membuka layanan dan mengatur proses pembersihan pada saat tidak sedang banyak pasien.

2. Sebaiknya Puskesmas mempersiapkan satu atau dua tenaga medis yang handal dan berpengalaman di tiap-tiap poli.

3. Sebaiknya pihak Puskesmas mempersiapkan $x$-banner alur pelayanan disamping pintu masuk.

4. Sebaiknya Puskesmas mengadakan pelatihan penanganan penderita gawat darurat bagi tenaga medis.

\section{KESIMPULAN}

Berdasarkan hasil penelitian pada analisis kualitas pelayanan Puskesmas Parit Haji Husin II diperoleh kesimpulan sebagai berikut:

1. Dengan melihat hasil perhitungan servqual, diperoleh enam variabel yang bernilai negatif. Keenam variabel tersebut yaitu perhatian terhadap keluhan pasien, kebersihan, kerapian dan kenyamanan ruangan, jadwal pemeriksaan yang tepat waktu, tindakan cepat pada saat pasien membutuhkan medis, prosedur pelayanan tidak berbelit-belit, dan pelayanan penerimaan cepat dan tepat. Enam variabel yang bernilai negatif menunjukkan bahwa pelayanan di Puskesmas Parit Haji Husin II belum mampu memenuhi harapan pasien, sehingga variabel yang bernilai negatif akan dilakukan perbaikan.

2. Berdasarkan hasil analisis TRIZ diperoleh usulan perbaikan yaitu:

a. Puskesmas Parit Haji Husin II memindahkan kotak pengaduan didepan loket.

b. Petugas dapat mengatur waktu proses pembersihan yang dapat dilakukan bila sedang tidak banyak pasien.

c. Kepala Puskesmas memwajibkan apel pagi kepada petugas puskesmas jika melanggar diberikan sangsi teguran pada saat petugas yang melanggar mengikuti apel pagi selanjutnya.

d. Puskesmas memasang $x$-banner alur pelayanan di depan pintu masuk.

e. Puskesmas mempersiapkan satu atau dua petugas yang berjaga di tiap-tiap poli.

f. Puskesmas memberikan pelatihan penanganan pasien gawat darurat bagi tenaga medis.

\section{DAFTAR PUSTAKA}

[1]. Pohan, I.S. Jaminan Mutu Layanan Kesehatan: Dasar-Dasar Pengertian dan Penerapan. EGC. Jakarta; 2006.

[2]. Wijaya, T. Manajemen Kualitas Jasa Desain Servqual, QFD, dan Kano. Indeks, Jakarta; 2018. 
[3]. Bernadhi, B.D., Baihaqi, I. dan Partiwi, S.G. Perancangan Stasiun Pengajaran Interaktif yang Berbiaya Murah. Prosiding Seminar Nasional Manajemen Teknologi XXI. Institut Teknologi Sepuluh Nopember. 2014.

[4]. Savransky, S.D. Engineering of Creativity (Introduction to TRIZ Methodology of Inventive Problem Solving). CRC Press. New York; 2000.

[5]. Rahmanti, H.W., Effendi, U. dan Astuti, R. Analisis Peningkatan Kualitas Pelayanan Menggunakan Metode Service Quality (Servqual) dan TRIZ (Studi Kasus Pada "Restoran Ocean Garden" Malang). Jurnal Teknologi Pertanian. 2017. 8(1):33-44.

[6] Supranto, J. Statistik Teori dan Aplikasi. Erlangga. Jakarta; 2000.

[7] Hidayat, A.A. Metode Penelitian Keperawatan dan Teknik nalisis Data. Salemba Medika. Jakarta; 2007.

SYAFITRI WULANDARI $\quad$ : Jurusan Matematika FMIPA Untan, Pontianak, syafitriwulandari23@gmail.com

EVY SULISTIANINGSIH $\quad$ : Jurusan Matematika FMIPA Untan, Pontianak, evysulistianingsih@math.untan.ac.id

NURFITRI IMRO'AH : J Jurusan Matematika FMIPA Untan, Pontianak, nurfitriimroah@math.untan.ac.id 